\title{
Kekik ile Doğal Boyama Yapılan Hatay İpeğinin Haslık Sonuçlarının Çok Kriterli Karar Verme Yöntemiyle En Uygun Seçeneğinin Belirlenmesi
}

\author{
Meral Özomay* \\ * Marmara Üniversitesi, Teknoloji Fakültesi, Tekstil Mühendisliği Bölümü, İstanbul, Türkiye, (ORCID: 0000-0003-0138-0060), meralozomay@gmail.com
}

(İlk Geliş Tarihi 15 Ekim 2021 ve Kabul Tarihi 6 Aralık 2021)

(DOI: 10.31590/ejosat.1010330)

\begin{abstract}
ATIF/REFERENCE: Özomay, M. (2021). Kekik ile Doğal Boyama Yapılan Hatay İpeğinin Haslık Sonuçlarının Çok Kriterli Karar Verme Yöntemiyle En Uygun Seçeneğinin Belirlenmesi. Avrupa Bilim ve Teknoloji Dergisi, (31), 531-538.

$\ddot{O} z$

Bu çalı̧̧mada Hatay İpeği ele alınmıştır. Türkiye'nin güneyinde, genellikle Hatay'ın ilçelerinde mahalli tezgâhlarda dokunarak örtünme veya çeşitli giyim eşyası olarak kullanılmaktadır. Bu çalışmada doğal ekru renkteki ipek kozasından elde edilen iplikle dokunmuş Hatay İpeği'nin renklendirilmesi üzerinde çalışılmıştır. Bu amaçla Akdeniz Bölgesi’nde sıklıkla yetiştirilen bir bitki olan kekik bitkisi boya için tercih edilmiş ve 3 farklı mordanın toplamda 15 farklı konsantrasyonu ile boyanmıştır. Boyanan Hatay İpeği numunelerinin yıkama haslıkları ile ışık haslıkları yapılarak, CIE $L^{*} \mathrm{a} * \mathrm{~b}$ renk uzay sisteminde hesaplanan renk farkları ve renk verimlilikleri karşılaştırılmıştır. Uygun boyama reçetesinin belirlenmesi için Gri İlişkisel Analiz Yöntemi kullanılmıştır. Çok kriterli karar verme yöntemlerinden biri olan Gri İlişkisel Analiz (Grey Relational Analysis) az ya da çok ve farklı seviyede bilgi, çoklu kriter ve karar vermenin karmaşık olduğu durumlarda başvurulabilecek etkili bir yöntemdir. Bu çalışmanın amacı, geleneksel el sanatlarının yaşatılması, bölgesel iş gücü istihdamının güçlendirilmesi, iç ve dış pazarlarda ürün payının artırılması için Hatay İpeği üreticilerine doğru doğal boya reçetesi ile destek olmaktır. Hatay İpeği'nin kekikle boyanmasında yıkama ve 1şı haslığı sonrası minimum renk fark1 ve maksimum renk verimi değerleri elde etmek için kullanılacak en iyi boyama özellikleri Quercus Aegilops doğal mordanı ile \%20 konsantrasyonda kullanılarak elde edilmiştir.
\end{abstract}

Anahtar Kelimeler: Hatay İpeği, Çok Kriterli Karar Verme, Gri İlişkisel Analiz, Doğal Boyama.

\section{Determination of The Most Suitable Option of The Fastness Results of Hatay Silk Made of Natural Dyeing with Thymus Vulgaris by Multi- Criteria Decision-Making Method}

\begin{abstract}
Hatay Silk is discussed in this study. In the south of Turkey, it is generally used as a covering or various clothing items by weaving on local looms in the districts of Hatay. In this study, it was studied on the coloring of Hatay Silk woven with yarn obtained from natural ecru silk cocoon. For this purpose, thyme plant, which is a plant frequently grown in the Mediterranean Region, was preferred for dye and dyed with a total of 15 different concentrations of 3 different mordants. Color differences and color efficiency calculated in CIE L*a*b color space system were compared by making the washing fastness and light fastness of dyed Hatay Silk samples. Gray Relational Analysis Method was used to determine the appropriate dyeing recipe. Gray Relational Analysis, which is one of the multicriteria decision-making methods, is an effective method that can be applied in situations where more or less information, multiple criteria and decision making are complex. The aim of this study is to support Hatay Silk producers with the right natural dye recipe in order to keep traditional handicrafts alive, strengthen regional workforce employment, and increase the product share in domestic and foreign markets. In order to obtain minimum color difference and maximum color yield values after washing and light fastness in dyeing Hatay Silk with thyme, the best dyeing properties were obtained by using Quercus Aegilops natural mordant at $20 \%$ concentration.
\end{abstract}

Keywords: Hatay Silk, Multi-Criteria Decision Making, Grey Relational Analysis, Natural Dyeing

*Sorumlu Yazar: meralozomay@gmail.com 


\section{Giriş}

İpekböcekçiliği üretimi, bugün de tıpkı eskiden olduğu gibi aynı ve doğal yöntemlerle üretilmeye devam etmektedir (Yurtoğlu, 2017; Hayat et. Al, 2021). İpekböceği yetiştiriciliği ve dokumacılığı emek yoğun bir faaliyet alanı olmasına rağmen halen ülkemiz istihdamına ve kültürüne katkı sağlayan bir iş koludur (Yılmaz, 2020). Geleneksel yöntemlerle üretilen ipek iplikleri yine geleneksel tezgahlarda dokunarak kumaş haline gelmekte ve nihai tüketiciye ulaştırılmaktadır (Akgül, 2021, Yanar \& Erdoğan, 2019).

Hatay'da ipek böceği kozası ile ipek üretimi tarihe karışırken baba mesleği diye devam etmeye çalışan bazı aileler tarafindan yaşatılmaya çalışılmakta ve Türkiye'ye tanıtılmaktadır (Kayabaşı, Karakelle \& Söylemezoğlu, 2016).

Günümüzde Harbiye'de 'Büyükaşık', Samandağı'nda 'Arat' aileleri ipekli dokumacılığı ikinci ve üçüncü kuşaklara aktarmaya çalışan ailelerdendir (Eraslan, 2009). Hatay'da el dokumacılığı yapan her aile aynı zamanda ipek böceği yetiştiricisidir (Saçlı \& Öztürk, 2020) ve Hatay ipekçiliği ve el dokumacılığı, babadan oğula geçen bir sanat kolu haline gelmiştir (Eraslan, 2009).

Kekik (Thymus vulgaris) türüne aittir (Sokat, 2021; Yüksek et. al., 2021; Batool et. al., 2021). Daha çok baharat olarak kullanılan kekik sarı renk boyamalar için ülkemizde Toros Dağlarındaki köylerde yün boyamacılığında kullanılmış ve haslıkları yüksek boyamalar elde edilmiştir (Hasan \& Balos, 202; Akkaya, 2008). Türkiye'de Origanum, Thymus, Thymbra, Saturaje, Sideritis ve Salvia cinsi kekiklerin yoğun olarak yetiştiği bilinmektedir (Bardakçı \& Yılmazer, 2007; Çelik \& Ayran, 2020). Kekikteki uçucu yağlar timol ve karvakrol (Şekil 1) bileşenleri içerir. Bu maddeler, kekiğe özgü kokusunu veren ve antioksidan özellik kazandıran fenolik bileşiklerdir (Ural, Özomay \& Özdemir, 2018). Kekik bitkisinin içerdiği boyarmadde Luteolin'dir. Uçucu yağların bazı test mikroorganizmalarına karşı bakteriyo statik aktivitelerinin olduğu ve sentetik antibiyotiklere alternatif olabileceği belirtilmektedir (Ezgi \& Bulut, 2013; Wojdyło, Oszmiański \& Czemerys, 2007).
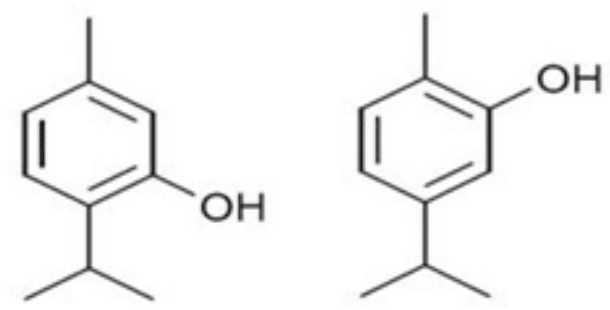

Şekil 1. Thymus vulgaris bitkisindeki temel yap1 (timol ve karvakrol)

Doğal boyalara olan ilgi ekolojik ve çevresel kaygıların artmasıyla birlikte doğru orantılı bir şekilde gün geçtikçe artmaktadır. Çevre, üretim ve tüketim ekolojisi birlikte değerlendirildiğinde, çevresel (biyo-çözünürlüğe sahip) ve kanserojen, alerjik etki gibi sağlık problemlerine yol açmayan, üretim güvenliği olan doğal boyaların kullanılması ile ilgili çalışmalar hız kazanmıştır. Ayrıca kekik bitkisinin antimikrobiyal özelliklerin incelendiği (Benli \& Yiğit, 2005; Rehman et. al., 2021), oksijen plazma ile sslanma özellikleri geliştirilen pamuk, keten ve poliester materyaller, kitosan ve kekik yağı ile işlem gördükten sonra antimikrobiyal özelliklerin geliştiği (Surdu et. al., 2014; Adeel et. al., 2021), Candida albican mantarına karşı antifungal etkinin incelendiği çalışmalar vardir (Vasconcelos et al., 2014).

$\mathrm{Al}$ (III), Fe (II), Sn (II) and $\mathrm{Cu}$ (II) mordanlarının kekik ekstraktındaki boya kompleksleri çöktürülerek HPLC-DAD ve FTIR analizi ile yapısal karakterizasyonları ve pigmentlerin termal dayanımı, termal bozunması ve termogravimertik analizleri (TGA) belirlenmiştir. Ayrıca antimikrobiyal aktivite de incelenmiş ve doğal boyada apigenin ve luteolin (Şekil 2) flavonlarının temel bileşen olduğu belirlenmiştir. Kekikten elde edilen boyanın antimikrobiyal aktivite gösterdiği, kaplama, boyama ve plastik endüstrisi için potansiyel uygulama alanı olabileceği belirtilmektedir Cakmakçi et. al., 2014).

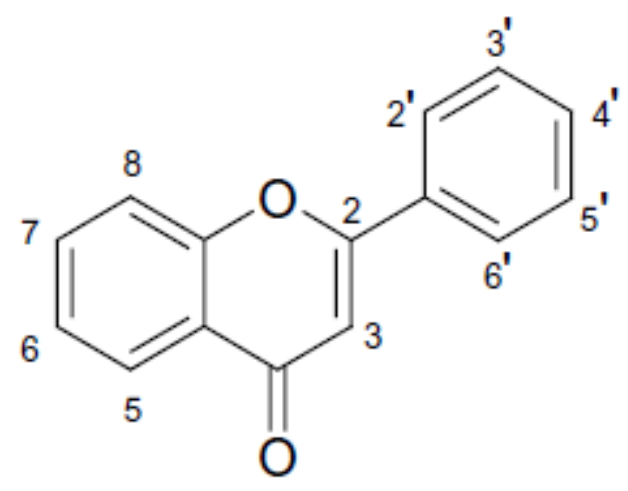

$$
\begin{aligned}
& \text { Apigenin (4', 5, } 7 \text { - OH) } \\
& \text { Luteolin (3', 4', 5, } 7 \text { - OH) }
\end{aligned}
$$

Şekil 2. Thymus vulgaris bitkisindeki temel fenolik bileşenler

\%100 yünlü kumaşın Mentha spicata L. ve Thymus vulgaris L. bitki kaynaklarından elde edilen boyalar ile demir (II) sülfat mordanı kullanılarak yapılan boyamalarında kekikte kahverengi renk tonlarının elde edildiği ve $\mathrm{K} / \mathrm{S}$ renk verimi ve haslık sonuçlarına göre kekik bitkisinin doğal boya kaynağı olarak kullanılabileceği belirtilmiştir (Arlı, Kayabaşı \& Ilgaz 1993; Tutak, Gülcan \& Akman, 2014). Kullanılan mordana bağlı olarak Thymus türlerinin toprak üstü aksamlarından sarı, kahverengi, yeşil-gri renkler elde edilebileceği açıklanmaktadır (Arslan \& K1z1l, 2001; Akkaya \& Eyupoglu 2016; Khan et al., 2021).

İçerisinde kekik bitkisinin de yer aldığ 1 birçok bitki ekstraktından elde edilen boyaların lif boyama kapasitesi, antioksidan potansiyeli kolorimetrik, kromatografik yöntemler ve demir tiosiyanat deneyi [ferric thiocyanate assay (FTC)] yöntemi ile incelenmiştir. Thymus vulgaris bitki ekstraktının da yüksek antioksidant etkisi olduğu, selüloza afinitesinin yüksek olduğu ve kenevir lifinde koyu parlak tonlar elde edildiği belirtilmektedir (Guinot et. al., 2007; Sundhu et. al.,2021; Habib et. al., 2021 ).

Kekik ve nar kabuğu kaynaklı doğal boyalar ile boyanmış pamuklu materyallerin renk, antimikrobiyal ve haslik özelliklerinin incelendiği araştırmada ekolojik problemlere 
neden olan ağır metal tuzları yerine potasyum alüminyum sülfat, bakır (II) sülfat, demir (II) sülfat ve kalay (II) klorür kullanılmış, mordanlanmamış örneklerle mordanlanmış örnekler, renk kuvveti $(\mathrm{K} / \mathrm{S})$, renk değerleri ve haslık özellikleri açısından karşılaştırılmıştır. Boyamalarda mordanlanmamış örneklerde antimikrobik özellik görülmezken mordanlandıktan sonra boyanmış örneklerin antimikrobik özelliklerinin geliştiği belirtilmektedir (Davulcu et. al., 2014; Ozomay et al., 2019).

Zirkonyum nano parçacıklarının önce sentez edilerek yüne uygulandığı ve ardından kekik bitkisi kaynaklı boya ile boyama yapıldığı çalışmada güç tutuşurluk ve antibakteriyel özellikler araştırılmıştır. $\% 1,3,6$ ve 9 oranında zirkomyum nano parçacıklar mordan olarak materyale uygulanmış ve zirkonyumdaki değişimler Fourier dönüşümlü kızılötesi spektroskopi ile (Fourier-transform infrared spectra-FTIR) analiz edilmiştir. Örneklerin güç tutuşurluk testleri yatay güç tutuşurluk testi (horizontal flammability test- HFT) ile yapılmış, antibakteriyel özellikler de gram-negatif bacterium E.coli ve gram-pozitif bacterium Staphylococcus aureus un büyüme azalması ile tayin edilmiştir. İşlem görmemiş ve görmüş kumaşların yüzey analizleri taramalı elektron mikroskobu ile (scanning electron microscopy-SEM) belirlenmiştir (Taheri et. al., 2015; Ozomay et. al., 2021; Söz et. al., 2021).

\section{Materyal ve Metot}

$\mathrm{Bu}$ çalışmada boyama parametrelerinin optimizasyonu için Gri İlişkisel Analizi (GİA) Yöntemi kullanılmıştır. Çok kriterli karar verme yöntemlerinden biri olan GİA, her geçen gün kendine daha fazla yer bulan ve farklı alanlardaki uygulamalarda kullanılan bir yöntemdir. Çok kriterli, karmaşık ve zor olan kararlarda başvurulabilecek etkili bir yöntemdir. Bu çalışmada, $\% 100$ pamuk ipliğiyle dokunan ve Türkiye'nin yöresel dokumalarından olan Hatay İpeği, ön mordanlama yöntemi ile 3 farklı mordanda 5 farklı konsantrasyonla mordanlanmıştır. $\mathrm{C}_{6} \mathrm{H}_{8} \mathrm{O}_{7}$ (Sitrik Asit) mordan1 ile $\% 2, \% 4, \% 6, \% 8, \% 10$ konsantrasyonlarda, $\mathrm{KAl}\left(\mathrm{SO}_{4}\right)_{2} .12 \mathrm{H}_{2} \mathrm{O}$ (Potasyum Alüminyum Sülfat) mordanı ile $\% 3, \% 5, \% 10, \% 15, \% 20$ konsantrasyonlarda ve doğal mordan olarak kullanılan Quercus Aegilops (Meşe Palamudu) bitkisi ile de $\% 3, \% 5, \% 10, \% 15$ ve $\% 20$ konsantrasyonlarda $1 / 100$ Flotte oranında $100^{\circ} \mathrm{C}^{\prime} \mathrm{de} 60 \mathrm{dk}$. süre ile kaynatılarak mordanlanmıştır. 24 saat bu banyoda bekletildikten sonra kurutulmuşlardır. Kekik bitkisi kullanılarak elde edilen ekstrakttan numune gramajı baz alınarak \%100 oranında bitki oranında ekstrakt kullanılmıştır. Mordanlanan numuneler yine 1/100 Flotte oranında \%100 bitki kullanarak $100^{\circ} \mathrm{C}$ 'de $60 \mathrm{dk}$. süre ile kaynatılarak boyanmıştır. 24 saat bu banyoda bekletildikten sonra kurutulmuşlardır. Boyanmış, numunelerin yıkama haslıkları, ISO 105-C06 standardına göre [ISO 105- C06] yıkama haslığı test makinesinde (Gyrowash / James H. Heal Co. Ltd.) gerçekleştirilmiş, ve renk farkları, lekelemeleri ve renk verimi spectrofotometre (Datacolor SF600+) ile tespit edilmiştir. Işık haslıkları ise ISO 105 - B02 ISO standardına göre [TS 1008 EN ISO 105-B02] 1şık haslığ test cihazında (James H. Heal) uygulanmıştır.

Tablo 1. Deney verileri kısaltmaları

\begin{tabular}{|c|c|c|c|}
\hline KOD & Açıklama & KOD & Açıklama \\
\hline$\Delta \mathrm{E}$ & Mordansıza Göre Renk Farkı & $1-\mathrm{D}$ & $\% 8 \mathrm{C}_{6} \mathrm{H}_{8} \mathrm{O}_{7}$ \\
\hline$\Delta \mathrm{E} \mathrm{Y}$ & Y1kama Haslığı (Renk Değgişimi) & $1-\mathrm{E}$ & $\% 10 \mathrm{C}_{6} \mathrm{H}_{8} \mathrm{O}_{7}$ \\
\hline$\Delta \mathrm{E} 1$ & Y1kama Haslığı (Lekeleme) Yün & $2-\mathrm{A}$ & $\% 3 \mathrm{KAl}\left(\mathrm{SO}_{4}\right)_{2} .12 \mathrm{H}_{2} \mathrm{O}$ \\
\hline$\Delta \mathrm{E} 2$ & Y1kama Haslığı (Lekeleme) Poliakrilonitril & $2-\mathrm{B}$ & $\% 5 \mathrm{KAl}\left(\mathrm{SO}_{4}\right)_{2} .12 \mathrm{H}_{2} \mathrm{O}$ \\
\hline$\Delta \mathrm{E} 3$ & Y1kama Haslığı (Lekeleme) Poliester & $2-\mathrm{C}$ & $\% 10 \mathrm{KAl}\left(\mathrm{SO}_{4}\right)_{2} .12 \mathrm{H}_{2} \mathrm{O}$ \\
\hline$\Delta \mathrm{E} 4$ & Y1kama Haslığı (Lekeleme) Poliamid & $2-\mathrm{D}$ & $\% 15 \mathrm{KAl}\left(\mathrm{SO}_{4}\right)_{2} .12 \mathrm{H}_{2} \mathrm{O}$ \\
\hline$\Delta \mathrm{E} 5$ & Yıkama Haslığı (Lekeleme) Pamuk & $2-\mathrm{E}$ & $\% 20 \mathrm{KAl}\left(\mathrm{SO}_{4}\right)_{2} .12 \mathrm{H}_{2} \mathrm{O}$ \\
\hline$\Delta \mathrm{E} 6$ & Yıkama Haslığı (Lekeleme) Asetat & $3-\mathrm{A}$ & $\% 3$ Quercus Aegilops \\
\hline$\Delta \mathrm{E} \mathrm{I}$ & Işık Haslığı & $3-\mathrm{B}$ & $\% 5$ Quercus Aegilops \\
\hline $\mathrm{K} / \mathrm{S}$ & Renk Verimi (Absorbsiyon katsayıları/Saçınım katsayıları) & $3-\mathrm{C}$ & $\% 10$ Quercus Aegilops \\
\hline $1-\mathrm{A}$ & $\% 2 \mathrm{C}_{6} \mathrm{H}_{8} \mathrm{O}_{7}$ & $3-\mathrm{D}$ & $\% 15$ Quercus Aegilops \\
\hline $1-\mathrm{B}$ & $\% 4 \mathrm{C}_{6} \mathrm{H}_{8} \mathrm{O}_{7}$ & $3-\mathrm{E}$ & $\% 20$ Quercus Aegilops \\
\hline $1-\mathrm{C}$ & $\% 6 \mathrm{C}_{6} \mathrm{H}_{8} \mathrm{O}_{7}$ & 0 & Mordansiz \\
\hline
\end{tabular}




\section{Araştırma Sonuçları ve Tartışma}

Tablo 2. Renk farkı ve renk verimi deney sonuçları

\begin{tabular}{|c|c|c|c|c|c|c|c|c|c|c|}
\hline Mordan & $\Delta \mathbf{E}$ & $\Delta E Y$ & $\Delta \mathrm{E} 1$ & $\Delta \mathrm{E} 2$ & $\Delta \mathrm{E} 3$ & $\Delta \mathrm{E} 4$ & $\Delta \mathrm{E} 5$ & $\Delta \mathrm{E} 6$ & $\Delta \mathrm{E} I$ & $\mathbf{K} / \mathbf{S}$ \\
\hline $1-\mathrm{A}$ & 2,397 & 2,105 & 1,177 & 1,281 & 0,706 & 0,8 & 1,585 & 3,677 & 7,277 & 10,35 \\
\hline $1-B$ & 2,071 & 3,777 & 0,995 & 1,082 & 0,653 & 0,75 & 1,93 & 3,152 & 7,104 & 9,17 \\
\hline $1-\mathrm{C}$ & 3,559 & 3,131 & 1,034 & 1,199 & 0,603 & 0,507 & 2,406 & 4,587 & 4,931 & 8,82 \\
\hline 1-D & 2,646 & 7,456 & 0,863 & 1,238 & 0,513 & 0,832 & 2,476 & 3,689 & 6,15 & 10,46 \\
\hline $1-E$ & 2,586 & 4,893 & 1,214 & 0,976 & 0,428 & 0,701 & 2,73 & 4,335 & 5,37 & 9,05 \\
\hline $2-\mathrm{A}$ & 7,633 & 3,568 & 1,012 & 1,485 & 0,61 & 0,967 & 1,961 & 4,19 & 5,474 & 10,36 \\
\hline $2-B$ & 9,924 & 1,496 & 1,294 & 1,893 & 1,18 & 1,307 & 2,878 & 2,786 & 9,786 & 10,92 \\
\hline $2-\mathrm{C}$ & 7,682 & 3,607 & 1,081 & 1,202 & 0,617 & 0,889 & 3,193 & 3,828 & 5,789 & 13,66 \\
\hline $2-\mathrm{D}$ & 16,859 & 4,02 & 1,139 & 1,182 & 0,567 & 0,671 & 1,583 & 3,449 & 7,71 & 10,34 \\
\hline $2-\mathrm{E}$ & 3,704 & 4,561 & 0,82 & 0,9 & 0,623 & 0,714 & 2,077 & 3,499 & 6,696 & 9,35 \\
\hline $3-\mathrm{A}$ & 14,014 & 1,736 & 1,033 & 1,537 & 1,014 & 1,229 & 3,327 & 4,258 & 6,533 & 11,88 \\
\hline $3-B$ & 3,906 & 3,019 & 1,02 & 1,833 & 0,916 & 1,144 & 2,969 & 3,4593 & 6,381 & 10,64 \\
\hline $3-\mathrm{C}$ & 14,669 & 7,965 & 1,884 & 1,511 & 0,795 & 1,155 & 1,521 & 2,803 & 7,642 & 9,77 \\
\hline $3-\mathrm{D}$ & 1,103 & 3,006 & 1,113 & 1,056 & 0,897 & 0,706 & 2,378 & 4,146 & 4,216 & 8,95 \\
\hline $3-\mathrm{E}$ & 7,284 & 3,197 & 0,971 & 0,929 & 0,379 & 0,777 & 3,228 & 3,337 & 7,254 & 11,44 \\
\hline 0 & $*$ & 27,994 & 1,307 & 1,769 & 1,248 & 1,61 & 4,016 & 4,008 & 4,326 & 9,89 \\
\hline
\end{tabular}

Hatay İpeği'nin kekik bitkisiyle 3 farklı mordanla boyanmasıyla yıkama ve 1şık haslığı sonrası elde edilen $\Delta \mathrm{E}$ farkları ve renk verimi sonuçları Tablo 2.'de toplu olarak verilmiştir. Mordansız boyamaya göre en büyük renk fark1 $\mathrm{KAl}\left(\mathrm{SO}_{4}\right)_{2} \quad .12 \quad \mathrm{H}_{2} \mathrm{O}$ mordanının \%15 konsantrasyonu ile yapılan boyamadan elde edilirken en düşük renk farkı Quercus Aegilops doğal mordanının \%15 konsantrasyonu ile yapılan boyamadan elde edilmiştir. Tabloya göre yıkama sonrası renk değişimi en yüksek numune mordansız yapılan boyamadan elde edilmiştir. Asetat, Pamuk, Poliamid, Poliester, Poliakrilonitril ve Yüne lekelemeler açısından mordanlar arasında belirgin bir farklılık oluşmamıştır. Yapılan 1şık haslığ1 sonucu elde edilen renk fark1 ve renk verimi değerlerine baktığımızda tüm mordanların bütün konsantrasyonları arasında ciddi bir farklılık olmadığı görülmektedir.

Tablo 3. Deneylerden elde edilen sonuçlar

\begin{tabular}{|c|c|c|c|c|c|c|c|c|c|}
\hline KOD & $\Delta E Y$ & $\Delta \mathrm{E} 1$ & $\Delta \mathrm{E} 2$ & $\Delta \mathrm{E} 3$ & $\Delta \mathrm{E} 4$ & $\Delta \mathrm{E} 5$ & $\overline{\Delta E} 6$ & $\overline{\Delta E} \mathbf{I}$ & K/S \\
\hline Referans & 1,496 & 0,82 & 0,9 & 0,379 & 0,507 & 1,521 & 2,786 & 4,216 & 13,66 \\
\hline $1-\mathrm{A}$ & 2,105 & 1,177 & 1,281 & 0,706 & 0,800 & 1,585 & 3,677 & 7,277 & 10,35 \\
\hline $1-B$ & 3,777 & 0,995 & 1,082 & 0,653 & 0,750 & 1,930 & 3,152 & 7,104 & 9,17 \\
\hline $1-\mathrm{C}$ & 3,131 & 1,034 & 1,199 & 0,603 & 0,507 & 2,406 & 4,587 & 4,931 & 8,82 \\
\hline 1-D & 7,456 & 0,863 & 1,238 & 0,513 & 0,832 & 2,476 & 3,689 & 6,150 & 10,46 \\
\hline 1 -E & 4,893 & 1,214 & 0,976 & 0,428 & 0,701 & 2,730 & 4,335 & 5,370 & 9,05 \\
\hline 2-A & 3,568 & 1,012 & 1,485 & 0,610 & 0,967 & 1,961 & 4,190 & 5,474 & 10,36 \\
\hline $2-B$ & 1,496 & 1,294 & 1,893 & 1,180 & 1,307 & 2,878 & 2,786 & 9,786 & 10,92 \\
\hline $2-\mathrm{C}$ & 3,607 & 1,081 & 1,202 & 0,617 & 0,889 & 3,193 & 3,828 & 5,789 & 13,66 \\
\hline $2-\mathrm{D}$ & 4,020 & 1,139 & 1,182 & 0,567 & 0,671 & 1,583 & 3,449 & 7,710 & 10,34 \\
\hline $2-\mathrm{E}$ & 4,561 & 0,820 & 0,900 & 0,623 & 0,714 & 2,077 & 3,499 & 6,696 & 9,35 \\
\hline 3-A & 1,736 & 1,033 & 1,537 & 1,014 & 1,229 & 3,327 & 4,258 & 6,533 & 11,88 \\
\hline 3-B & 3,019 & 1,020 & 1,833 & 0,916 & 1,144 & 2,969 & 3,459 & 6,381 & 10,64 \\
\hline $3-\mathrm{C}$ & 7,965 & 1,884 & 1,511 & 0,795 & 1,155 & 1,521 & 2,803 & 7,642 & 9,77 \\
\hline 3-D & 3,006 & 1,113 & 1,056 & 0,897 & 0,706 & 2,378 & 4,146 & 4,216 & 8,95 \\
\hline $3-\mathrm{E}$ & 3,197 & 0,971 & 0,929 & 0,379 & 0,777 & 3,228 & 3,337 & 7,254 & 11,44 \\
\hline MAX & 7,965 & 1,884 & 1,893 & 1,180 & 1,307 & 3,327 & 4,587 & 9,786 & 13,66 \\
\hline MIN & 1,496 & 0,820 & 0,900 & 0,379 & 0,507 & 1,521 & 2,786 & 4,216 & 8,82 \\
\hline
\end{tabular}


Tablo 3'e göre yıkama sonrası renk farkı ve lekelemelerin az olması daha iyi performansı göstermektedir. Renk verimi olan $\mathrm{K} / \mathrm{S}$ 'nin ise fazla olması daha iyi bir performansı göstermektedir.
Tabloda referans satırı oluşturularak, ilgili sütundaki verilerin hangi değere göre (Maksimum, Minimum ve İdeal değerlere göre) gri ilişkisinin hesaplandığını göstermektedir.

Tablo 4. Normalizasyon matrisi

\begin{tabular}{|c|c|c|c|c|c|c|c|c|c|}
\hline KOD & $\Delta E Y$ & $\Delta \mathrm{E} 1_{1}$ & $\Delta \mathrm{E} 2$ & $\Delta \mathrm{E} 3$ & $\Delta \mathrm{E} 4$ & $\Delta \mathrm{E} 5$ & $\overline{\Delta E} 6$ & $\Delta \mathrm{E} I$ & $\mathbf{K} / \mathbf{S}$ \\
\hline $1-\mathrm{A}$ & 0,9058 & 0,6644 & 0,6163 & 0,5917 & 0,6337 & 0,9645 & 0,5052 & 0,4504 & 0,3161 \\
\hline $1-B$ & 0,6473 & 0,8355 & 0,8167 & 0,6579 & 0,6962 & 0,7735 & 0,7967 & 0,4815 & 0,0723 \\
\hline $1-\mathrm{C}$ & 0,7472 & 0,7988 & 0,6988 & 0,7203 & 1 & 0,5099 & 0 & 0,8716 & 0 \\
\hline 1-D & 0,0786 & 0,9595 & 0,6596 & 0,8327 & 0,5937 & 0,4712 & 0,4986 & 0,6527 & 0,3388 \\
\hline 1-E & 0,4748 & 0,6296 & 0,9234 & 0,9388 & 0,7575 & 0,3305 & 0,1399 & 0,7928 & 0,0475 \\
\hline $2-A$ & 0,6797 & 0,8195 & 0,4108 & 0,7116 & 0,425 & 0,7563 & 0,2204 & 0,7741 & 0,3181 \\
\hline 2-B & 1 & 0,5545 & 0 & 0 & 0 & 0,2486 & 1 & 0 & 0,4338 \\
\hline $2-\mathrm{C}$ & 0,6736 & 0,7546 & 0,6958 & 0,7028 & 0,5225 & 0,0741 & 0,4214 & 0,7175 & 1 \\
\hline 2-D & 0,6098 & 0,7001 & 0,7160 & 0,7652 & 0,795 & 0,9656 & 0,6318 & 0,3727 & 0,3140 \\
\hline $2-E$ & 0,5262 & 1 & 1 & 0,6953 & 0,7412 & 0,6921 & 0,6041 & 0,5547 & 0,1095 \\
\hline $3-\mathrm{A}$ & 0,9628 & 0,7998 & 0,3585 & 0,2072 & 0,0975 & 0 & 0,1826 & 0,5840 & 0,6322 \\
\hline $3-B$ & 0,7645 & 0,8120 & 0,0604 & 0,3295 & 0,2037 & 0,1982 & 0,6261 & 0,6113 & 0,3760 \\
\hline $3-\mathrm{C}$ & 0 & 0 & 0,3846 & 0,4806 & 0,19 & 1 & 0,9905 & 0,3849 & 0,1962 \\
\hline $3-\mathrm{D}$ & 0,7665 & 0,7246 & 0,8429 & 0,3533 & 0,7512 & 0,5254 & 0,2448 & 1 & 0,0268 \\
\hline $3-\mathrm{E}$ & 0,7370 & 0,8580 & 0,9707 & 1 & 0,6625 & 0,0548 & 0,6940 & 0,4545 & 0,5413 \\
\hline MAX & 1 & 1 & 1 & 1 & 1 & 1 & 1 & 1 & 1 \\
\hline MIN & 0 & 0 & 0 & 0 & 0 & 0 & 0 & 0 & 0 \\
\hline
\end{tabular}

Tablo 4'te GİA yöntemine göre referans serisi oluşturulurken $\Delta \mathrm{E}$... değerleri için normalizasyon işlemi esnasında "Minimum; daha düşük daha iyi” şeklinde değerlendirilirken K/S değeri için "Maksimum; daha yüksek daha iyi" şeklinde değerlendirilmiştir.

Tablo 5. Uzaklık matrisi

\begin{tabular}{|c|c|c|c|c|c|c|c|c|c|}
\hline KOD & $\Delta E Y$ & $\Delta E 1$ & $\Delta \mathrm{E} 2$ & $\Delta \mathrm{E} 3$ & $\Delta E 4$ & $\Delta E 5$ & $\Delta E 6$ & $\Delta E I$ & K/S \\
\hline $1-\mathrm{A}$ & 0,0941 & 0,3355 & 0,3836 & 0,4082 & 0,3662 & 0,0354 & 0,4947 & 0,5495 & 0,6838 \\
\hline $1-B$ & 0,3526 & 0,1644 & 0,1832 & 0,3420 & 0,3037 & 0,2264 & 0,2032 & 0,5184 & 0,9276 \\
\hline $1-\mathrm{C}$ & 0,2527 & 0,2011 & 0,3011 & 0,2796 & 0 & 0,4900 & 1 & 0,1283 & 1 \\
\hline 1-D & 0,9213 & 0,0404 & 0,3403 & 0,1672 & 0,4062 & 0,5287 & 0,5013 & 0,3472 & 0,6611 \\
\hline $1-\mathrm{E}$ & 0,5251 & 0,3703 & 0,0765 & 0,0611 & 0,2425 & 0,6694 & 0,8600 & 0,2071 & 0,9524 \\
\hline $2-\mathrm{A}$ & 0,3202 & 0,1804 & 0,5891 & 0,2883 & 0,575 & 0,2436 & 0,7795 & 0,2258 & 0,6818 \\
\hline $2-B$ & 0 & 0,4454 & 1 & 1 & 1 & 0,7513 & 0 & 1 & 0,5661 \\
\hline $2-\mathrm{C}$ & 0,3263 & 0,2453 & 0,3041 & 0,2971 & 0,4775 & 0,9258 & 0,5785 & 0,2824 & 0 \\
\hline 2-D & 0,3901 & 0,2998 & 0,2839 & 0,2347 & 0,205 & 0,0343 & 0,3681 & 0,6272 & 0,6859 \\
\hline $2-E$ & 0,4737 & 0 & 0 & 0,3046 & 0,2587 & 0,3078 & 0,3958 & 0,4452 & 0,8904 \\
\hline $3-A$ & 0,0371 & 0,2001 & 0,6414 & 0,7927 & 0,9025 & 1 & 0,8173 & 0,4159 & 0,3677 \\
\hline $3-B$ & 0,2354 & 0,1879 & 0,9395 & 0,6704 & 0,7962 & 0,8017 & 0,3738 & 0,3886 & 0,6239 \\
\hline $3-\mathrm{C}$ & 1 & 1 & 0,6153 & 0,5193 & 0,81 & 0 & 0,0094 & 0,6150 & 0,8037 \\
\hline $3-\mathrm{D}$ & 0,2334 & 0,2753 & 0,1570 & 0,6466 & 0,2487 & 0,4745 & 0,7551 & 0 & 0,9731 \\
\hline $3-E$ & 0,2629 & 0,1419 & 0,0292 & 0 & 0,3375 & 0,9451 & 0,3059 & 0,5454 & 0,4586 \\
\hline MAX & 1 & 1 & 1 & 1 & 1 & 1 & 1 & 1 & 1 \\
\hline MIN & 0 & 0 & 0 & 0 & 0 & 0 & 0 & 0 & 0 \\
\hline
\end{tabular}


Normalize edilen sonuçlar referans değeri olan sütundaki en Tablo 5 'te elde edilmiştir.

büyük değer olan 1'den çıkarılarak gerekli olan uzaklık matrisi

Tablo 6. Gri ilişkisel derece matrisi

\begin{tabular}{lrrrrrrrrrrr}
\hline KOD & $\boldsymbol{\Delta E} \mathbf{Y}$ & $\boldsymbol{\Delta E} \mathbf{1}$ & $\mathbf{\Delta E} \mathbf{2}$ & $\boldsymbol{\Delta E} \mathbf{3}$ & $\boldsymbol{\Delta E} \mathbf{4}$ & $\boldsymbol{\Delta E} \mathbf{5}$ & $\boldsymbol{\Delta E} \mathbf{6}$ & $\boldsymbol{\Delta E} \mathbf{I}$ & $\mathbf{K} / \mathbf{S}$ & $\mathbf{G i D}$ & Sira \\
& & & & & & & & & & & \\
\hline 1-A & 0,913 & 0,748 & 0,722 & 0,710 & 0,731 & 0,965 & 0,669 & 0,645 & 0,593 & 0,74461 & 7 \\
1-B & 0,739 & 0,858 & 0,845 & 0,745 & 0,767 & 0,815 & 0,831 & 0,658 & 0,518 & 0,75323 & 4 \\
1-C & 0,798 & 0,832 & 0,768 & 0,781 & 1 & 0,671 & 0,5 & 0,886 & 0,5 & 0,74869 & 5 \\
1-D & 0,520 & 0,961 & 0,746 & 0,856 & 0,711 & 0,654 & 0,666 & 0,742 & 0,601 & 0,71777 & 10 \\
1-E & 0,655 & 0,729 & 0,928 & 0,942 & 0,804 & 0,599 & 0,537 & 0,828 & 0,512 & 0,72652 & 9 \\
2-A & 0,757 & 0,847 & 0,629 & 0,776 & 0,634 & 0,804 & 0,561 & 0,815 & 0,594 & 0,71348 & 11 \\
2-B & 1 & 0,691 & 0,5 & 0,5 & 0,5 & 0,570 & 1 & 0,5 & 0,638 & 0,65570 & 15 \\
2-C & 0,753 & 0,803 & 0,766 & 0,770 & 0,676 & 0,519 & 0,633 & 0,779 & 1 & 0,74490 & 6 \\
2-D & 0,719 & 0,769 & 0,778 & 0,809 & 0,829 & 0,966 & 0,730 & 0,614 & 0,593 & 0,75696 & 3 \\
2-E & 0,678 & 1 & 1 & 0,766 & 0,794 & 0,764 & 0,716 & 0,691 & 0,528 & 0,77126 & 2 \\
3-A & 0,964 & 0,833 & 0,609 & 0,557 & 0,525 & 0,5 & 0,550 & 0,706 & 0,731 & 0,66418 & 13 \\
3-B & 0,809 & 0,841 & 0,515 & 0,598 & 0,556 & 0,555 & 0,727 & 0,720 & 0,615 & 0,66010 & 14 \\
3-C & 0,5 & 0,5 & 0,619 & 0,658 & 0,552 & 1 & 0,990 & 0,619 & 0,554 & 0,66600 & 12 \\
3-D & 0,810 & 0,784 & 0,864 & 0,607 & 0,800 & 0,678 & 0,569 & 1 & 0,506 & 0,73577 & 8 \\
3-E & $\mathbf{0 , 7 9 1}$ & $\mathbf{0 , 8 7 5}$ & $\mathbf{0 , 9 7 1}$ & $\mathbf{1}$ & $\mathbf{0 , 7 4 7}$ & $\mathbf{0 , 5 1 4}$ & $\mathbf{0 , 7 6 5}$ & $\mathbf{0 , 6 4 7}$ & $\mathbf{0 , 6 8 5}$ & $\mathbf{0 , 7 7 7 6 9}$ & $\mathbf{1}$ \\
\hline
\end{tabular}

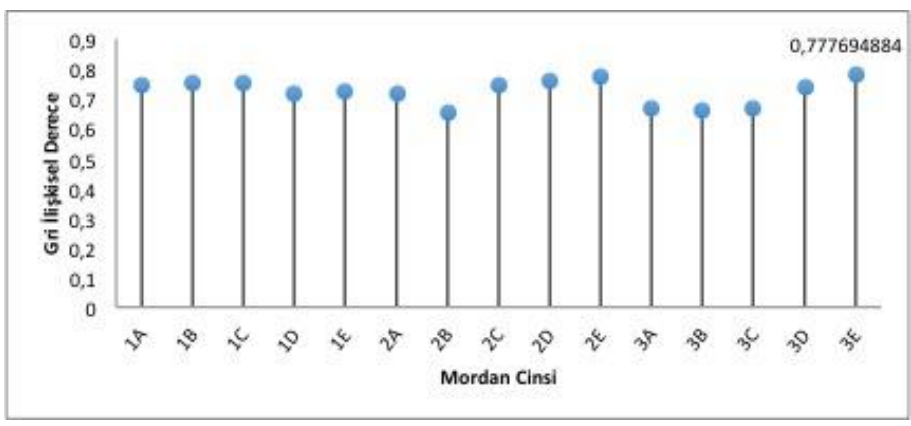

Şekil 3. Gri ilişkisel analizi

Tablo 6 ve Şekil 3'te Hatay İpeği'nin kekikle boyanmasında yıkama ve 1şık haslığı sonrası minimum renk fark1 ve maksimum renk verimi değerleri elde etmek için kullanılan reçetelerin Gri İlişkisel Analiz Yöntemi'ne göre sıralaması verilmiştir. Bu sıralamaya göre Hatay İpeği'nin kekik bitkisi ile renklendirilmesinde tercih edilmesi gereken mordan cinsi ve miktarı sıralaması:

1: \%20 Quercus Aegilops,

2: $\% 20 \mathrm{KAl}\left(\mathrm{SO}_{4}\right)_{2} .12 \mathrm{H}_{2} \mathrm{O}$

3: $\% 15 \mathrm{KAl}\left(\mathrm{SO}_{4}\right)_{2} .12 \mathrm{H}_{2} \mathrm{O}$

4: $\% 4 \mathrm{C}_{6} \mathrm{H}_{8} \mathrm{O}_{7}$

5: $\% 6 \mathrm{C}_{6} \mathrm{H}_{8} \mathrm{O}_{7}$

6: \% $10 \mathrm{KAl}\left(\mathrm{SO}_{4}\right)_{2} .12 \mathrm{H}_{2} \mathrm{O}$

7: $\% 2 \mathrm{C}_{6} \mathrm{H}_{8} \mathrm{O}_{7}$

8: \%15 Quercus Aegilops

9: $\% 10 \mathrm{C}_{6} \mathrm{H}_{8} \mathrm{O}_{7}$

e-ISSN: 2148-2683
10: $\% 8 \mathrm{C}_{6} \mathrm{H}_{8} \mathrm{O}_{7}$

11: $\% 3 \mathrm{KAl}\left(\mathrm{SO}_{4}\right)_{2} .12 \mathrm{H}_{2} \mathrm{O}$

12 H2O 12: \%10 Quercus Aegilops

13: \%3 Quercus Aegilops

14: \%5 Quercus Aegilops

15: $\% 5 \mathrm{KAl}\left(\mathrm{SO}_{4}\right)_{2} .12 \mathrm{H}_{2} \mathrm{O}$

\section{Sonuç}

Hatay İpeği'nin kekikle boyanmasında yıkama ve 1 şık haslığı sonrası minimum renk farkı ve maksimum renk verimi değerleri elde etmek için kullanılacak en iyi boyama özellikleri Quercus Aegilops doğal mordanı ile \%20 konsantrasyonda kullanılarak elde edilmiştir. En iyi ikinci sıradaki değer $\mathrm{KAl}\left(\mathrm{SO}_{4}\right)_{2} .12 \mathrm{H}_{2} \mathrm{O}$ mordanı ile sirasiyla \%20 konsantrasyonda gerçekleştirilmiştir. $\mathrm{C}_{6} \mathrm{H}_{8} \mathrm{O}_{7}$ mordanı kullanılarak yapılan boyamalarda en iyi değer $\% 4$ konsantrasyon ile elde edilirken en kötü değer $\% 8$ konsantrasyon ile elde edilmiştir. $\mathrm{C}_{6} \mathrm{H}_{8} \mathrm{O}_{7}$ mordanı ile yapılan boyamalarda konsantrasyon miktarına göre karışık bir sıralama oluşmuştur. $\mathrm{C}_{6} \mathrm{H}_{8} \mathrm{O}_{7}$ mordanı ile yapılan boyamalar sonucu elde edilen siralama en iyiden kötüye doğru $\% 4, \% 6, \% 2$, $\% 10$ ve $\% 8$ şeklindedir.

$\mathrm{KAl}\left(\mathrm{SO}_{4}\right)_{2} .12 \mathrm{H}_{2} \mathrm{O}$ mordanı ile yapılan boyamalar arasında en iyi değeri $\% 20$ konsantrasyonla yapılan boyama sonucu verirken en kötü değeri $\% 5$ konsantrasyon vermektedir. $\mathrm{KAl}\left(\mathrm{SO}_{4}\right)_{2} \quad .12 \quad \mathrm{H}_{2} \mathrm{O}$ mordan 1 ile yapilan boyamalarda \%5 konsantrasyondan \%20 konsantrasyona kadar mordan miktarını arttırdıkça daha iyi değere ulaşıldı̆̆ 1 tespit edilmiştir. $\mathrm{KAl}\left(\mathrm{SO}_{4}\right)_{2}$ $.12 \mathrm{H}_{2} \mathrm{O}$ mordanı ile yapılan boyamalar sonucu elde edilen sıralama en iyiden kötüye doğru $\% 20, \% 15, \% 10, \% 3$ ve $\% 5$ şeklindedir.

Quercus Aegilops doğal mordanı kullanılarak yapılan boyamalarda en iyi değer en yüksek konsantrasyon olan \%20 ile 
elde edilirken en kötü değer \%5 konsantrasyonla elde edilmiştir. Quercus Aegilops doğal mordanı ile yapılan boyamalarda \%5 konsantrasyondan \%20 konsantrasyona kadar mordan miktarını arttırdıkça daha iyi değere ulaşıldığı tespit edilmiştir. Quercus Aegilops doğal mordanı ile yapılan boyamalar sonucu elde edilen sıralama en iyiden kötüye doğru $\% 20, \% 15, \% 10, \% 3$ ve $\% 5$ şeklindedir.

İpek ipliklerde kekik ile yapılan boyamalar için tüm sonuçlar dikkate alındığında $\mathrm{KAl}\left(\mathrm{SO}_{4}\right)_{2} .12 \quad \mathrm{H}_{2} \mathrm{O}$ mordanının düşük konsantrasyonları ve Quercus Aegilops doğal mordanının düşük konsantrasyonları ile yapılan boyamaların yıkama ve $1 s ̧ 1 k$ haslıklarının diğer mordanlara göre daha düşük olduğu tespit edilmiştir.

\section{Teşekkür}

"Bu çalışma İstanbul Kalkınma Ajansı tarafindan TR10/18/YMP/0137 proje numarası ile desteklenmiştir.

\section{Kaynakça}

Akgül, K. (2021). Kırsal kalkınma bağlamında Türkiye'de ipek böcekçiliği: Bursa ili örneği (Master's thesis, Balıkesir Üniversitesi Sosyal Bilimler Enstitüsü).

Akkaya, M. (2008). Türkiye'de giyim eğitimi veren meslek liselerindeki öğrencilerin sanayi uygulamalarının işletmeler, öğrenciler ve koordinatör öğretmenler açısından değerlendirilmesi. Master tezi, Selçuk Üniversitesi Sosyal Bilimler Enstitüsü.

Akkaya, M., \& Eyupoglu, S. (2016). The examination of the effects of quercus aegilops extract used as natural mordant on colourfulness features of natural dyeing. In 2016 IEEE NW Russia Young Researchers in Electrical and Electronic Engineering Conference (EIConRusNW) (pp. 108-111). IEEE.

Ali Ahmad khan, Shahid Adeel, Muhammad Azeem and Naeem Iqbal. 2021. Exploring natural colorant behavior of husk of durum (Triticum durum Desf.) and bread (Triticum aestivum L.) wheat species for sustainable cotton fabric dyeing. Environmental Science and Pollution research. https://doi.org/10.1007/s11356-021-14241-6.

Arlı, M., Kayabaşı, N., \& Ilgaz, F. (1993). El Dokuması Halıcılıkta Bitkisel Boya Kullanımının Önemi. 1993 (Cilt: 7), 38.

Arslan, N., \& Kızıl, S. (2001). Boya Bitkileri. TİGEM, 79, 4851.

Bardakçı, B., \& Yılmazer, M. (2007). Isparta, Sütçüler Bölgesi Kekik Yağının Kimyasal Yapısının İncelenmesi. Süleyman Demirel Üniversitesi Fen Edebiyat Fakültesi Fen Dergisi, 2(1), 77-82.

Benli, M., \& Yiğit, N. (2005). Ülkemizde yaygın kullanımı olan kekik (Thymus vulgaris) bitkisinin antimikrobiyal aktivitesi. Orlab On-Line Mikrobiyoloji Dergisi, 3(8), 1-8.

Cakmakçi, E., Deveoglu, O., Muhammed, A., Fouad, A., Torgan, E., \& Karadag, R. (2014). HPLC-DAD analysis of Thymus serpyllum based natural pigments and investigation of their antimicrobial properties. Pigment \& Resin Technology.
Çelik, S. A.\& Ayran, İ. (2020). Antioksidan Kaynağı Olarak Bazı Tıbbi ve Aromatik Bitkiler. Türk Bilimsel Derlemeler Dergisi, 13(2), 115-125.

Davulcu, A., Benli, H., Şen, Y., \& Bahtiyari, M. I. (2014). Dyeing of cotton with thyme and pomegranate peel. Cellulose, 21(6), 4671-4680.

Eraslan, A. (2009). Antakya ve Çevresinde El Zanaatlar1/Handcraft in And Around Antioch. Mustafa Kemal Üniversitesi Sosyal Bilimler Enstitüsü Dergisi, 6(12), 373-402.

Ezgi, A. \& Bulut, M. (2013). Bazı tekstil boya bitkilerinin antibakteriyal özellikleri ve aktivitesi için kullanılan test yöntemleri. Teknik Bilimler Dergisi, 3(2), 1-6.

Fatima Batool, Shahid Adeel, Muhammad Azeem and Naeem Iqbal. 2021. Natural Dye Y1elding Potential And Compounds Of Selected Vegetable Residues Belonging To Brassicaceae: An Approach Towards Sustainability. Pakistan Journal of Botany 54(1): DOI: http://dx.doi.org/10.30848/PJB2022-1(39).

Fazal-ur-Rehman, Shahid Adeel, Tanvir Ahmad, Abdul Mateen and Nimra Amin. 2021. Statistical Optimization of Parameters for Eco-Friendly Dyeing of Cotton using Direct Red 31 Dye. Journal of Natural Fibers. https://doi.org/10.1080/15440478.2021.1951420

Guinot, P., Benonge, I., Nicolett, G., Gargadennec, A., Andary, C., \& Rapior, S. (2007). Combined dyeing and antioxidative properties of some plant by-products. Acta Botanica Gallica, 154(1), 43-52.

Hasan, A. \& Balos, M. M. (2021). Alkanna Strigosa Boiss. \&Hohen. (Boraginaceae) Kökünden Doğal Boya Eldesi. International Journal Of Life Sciences And Biotechnology, 4(2), 206-216.

Hayat, T., Adeel, S., Batool, F., Amin, N., Ahmad, T., \& Ozomay, M. (2021). Waste black tea leaves (Camelia sinensis) as a sustainable source of tannin natural colorant for bio-treated silk dyeing. Environmental Science and Pollution Research, 114.

Kayabaşı, N., Karakelle, A., \& Söylemezoğlu, F. (2016). Tasarımda Süsleme Malzemesi Olarak İpekböceği Kozasının Kullanımı: Hatay Örneği. Art-E Sanat Dergisi, 9(17), 233-245.

Maryam Sundhu, M. Kaleem Khosa, Shahid Adeel, Tanvir Ahmad. 2021. Microwave assisted eco-friendly acidic dyeing of proteinous fabrics using Acid Violet 3B Dye. Journal of Natural Fibers, https://doi.org/10.1080/15440478.2021.1958436

Noman habib, Shahid Adeel, Farhan Ali, Nimra Amin and Shahid Rehman Khan. 2021. Environmental friendly sustainable application of plant-based mordants for cotton dyeing using Arjun bark-based natural colorant. Environmental Science and Pollution research. (https://doi.org/10.1007/s11356-021-145368)

Özomay, M. (2016). Türkiye'de yöresel dokunan bez örneklerinin doğal boyarmaddeler ile gri ilişkisel analiz yöntemi kullanılarak boyama özelliklerinin belirlenmesi, Marmara Üniversitesi Fen Bilimleri Enstitüsü (Doctoral dissertation, Doktora Tezi).

Özomay, M., \& Özomay, Z. (2021). The Effect of Temperature and Time Variables on Printing Quality in Sublimation Transfer 
Printing on Nylon and Polyester Fabric. Avrupa Bilim ve Teknoloji Dergisi, (23), 882-891.

Özomay, M., Güngör, F., \& Özomay, Z. (2021). Determination of optimum dyeing recipe with different amount of mordants in handmade cotton fabrics woven with olive leaves by grey relational analysis method. The Journal of The Textile Institute, $1-10$.

Özomay, M., Özomay, Z., Türkmen, F. N., \& Özakhun, Ö. (2021). Kültürel Değerlerimiz Tekstil ve Yazma Eserlerde Tahribatsız ve Mikro Analiz Yöntemleri.

Özomay, Z., Aydemir, C., \& Özakhun, Ş. C. (2019). Determination Of The Most Suitable Option For Production With Uncoated Papers İn Offset Printing By Multi-Criteria Decision Making Method. Muş Alparslan Üniversitesi Fen Bilimleri Dergisi, 7(2), 667-672.

Saçlı, Ç., \& Öztürk, F. B. (2020). İpekçilik Kültürü ve Turizm: Paydaşların Hatay'da İpekçiliğe Yönelik Görüşleri. Elektronik Sosyal Bilimler Dergisi, 19(76), 1916-1930.

Shahid Adeel, Fazal-ur-Rehman, Khalid Mahmood Zia, Muhammad Azeem, Shumaila Kiran, Mohammad Zuber, Muhammad Irfan, Muhammad Abdul Qayyum. 2021. Microwave supported green dyeing of mordanted wool fabric with Arjun bark extracts. Journal of Natural Fibers. 18(1): 136150 .

Sokat, Y. (2021). Kekik Hasadı Sırasında Yabancı Otların Ürüne Karışma Durumu. Bahri Dağdaş Bitkisel Araştırma Dergisi, 10(1), 102-111.

Söz, Ç. K., Özomay, Z., Unal, S., Uzun, M., \& Sönmez, S. (2021). Development of a nonwetting coating for packaging substrate surfaces using a novel and easy to implement method. Nordic Pulp \& Paper Research Journal.

Surdu, L., Radulescu, I. R., Vamesu, M., Iordache, O., \& Dinca, L. (2014). Improvement of the anti-microbial character of woven fabrics through plasma treatment. Journal of Chemical Engineering and Chemistry Research, 1(2), 114-121.

Taheri, M., Maleknia, L., Ghamsari, N. A., Almasian, A., \& Fard, G. C. (2015). Effect of zirconium dioxide nanoparticles as a mordant on properties of wool with thyme: dyeing, flammability and antibacterial. Oriental Journal of Chemistry, $31(1), 85$.

Tutak, M., Gülcan, A. C. A. R., \& Akman, O. (2014). Nane (Mentha Spicata L.) Ve Kekik (Thymus Vulgaris L.) Bitkileri Kullanarak Yün Lifinin Doğal Boyanması. Tekstil Ve Mühendis, 21(93).

Ural, E., Özomay, Z., \& Özdemİr, L. (2018). Determination of the effect of palm oil ink on print quality. Mus Alparslan University Journal of Science, 6(1), 533-537.

Vasconcelos, L., Sampaio, F. C., Albuquerque, A. \& Vasconcelos, L. (2014). Cell viability of Candida albicans against the antifungal activity of thymol. Brazilian Dental Journal, 25, 277-281.

Wojdyło, A., Oszmiański, J., \& Czemerys, R. (2007). Antioxidant activity and phenolic compounds in 32 selected herbs. Food chemistry, 105(3), 940-949.

Yanar, A., \& Erdoğan, Z. (2019). Denizli Dokumalarının Kültürel Miras ve Coğrafi İşaretleme Bakımından Önemi.
Pamukkale Üniversitesi Sosyal Bilimler Enstitüsü Dergisi, (37), 43-51.

Y1lmaz, F. (2020). Ebegümeci Bitkisinin Doğal Boyarmadde Olarak Kullanılması. Tekstil ve Mühendis, 27(118), 84-90.

Yurtoğlu, N. (2017). Cumhuriyet Döneminde Türkiye'de İpek Böcekçiliği (1923-1950). Çağdaş Türkiye Tarihi Araştırmaları Dergisi, 17(34), 159-189.

Yüksek, V., Dede, S., Çetin, S., Akan, Z., Özdemir, H., Dikilidal, M., \& Oto, G. (2021). Deneysel Diyabet Oluşturulmuş Ratlarda Kekik (Thymus vulgaris L.) ve Karabaş Kekiği (Thymbra spicata L.) Uygulamasının Serum Protein Fraksiyonlarına Etkisi. Van Tip Dergisi, 28(2), 193-198. 